\title{
Outcome of buccal mucosa urethroplasty in the management of urethral strictures
}

\author{
Basri Cakiroglu $^{1}$, Orhun Sinanoglu ${ }^{2}$, Ersan Arda ${ }^{1}$ \\ ${ }^{1}$ Hisar Intercontinental Hospital Department of Urology, Umraniye, Istanbul, Turkey; \\ ${ }^{2}$ Maltepe University Medical School Department of Urology, Maltepe, Istanbul, Turkey.
}

\begin{abstract}
Summary Objective: The objective of the study is urethroplasty.

Materials and methods: The follow up data of 15 patients undergoing single stage urethroplasty from September 2010 to September 2015 were retropectively reviewed. They received buccal mucosa graft for urethroplasty. The patients were followed for complications and outcome.

Results: Mean age was $53.7 \pm 13.6$ The stricture length ranged from 3 to $6 \mathrm{~cm}$ (mean $4.4 \pm 0.8$ ). The success rate for buccal mucosa urethroplasty (BMU) was $67.7 \%$ at $12^{\text {th }}$ month.

Three patients presenting with voiding difficulty in the $3^{\text {rd }}$ month and one in the next 12 months, had urethral restenosis. One patient had fistula formation at $6^{\text {th }}$ month postoperatively. Five patients underwent retreatment procedures such as internal urethrotomy, urethroplasty and/or internal urethrotomy. Conclusions: The buccal mucosa is easy to obtain and handle, therefore BMU can be safely and effectively managed outside high volume institutions.
\end{abstract}

KEY WORDS: Urethral stricture; Buccal mucosa; Urethroplasty.

Submitted 2 March 2017; Accepted 15 April 2017

\section{INTRODUCTION}

Anterior urethral stricture is a pathological fibrous tissue development involving the corpus spongiousum. The most common etiology of anterior urethral stricture is trauma, mostly straddle injury. Several factors such as etiology of stricture, site, length and density of the fibrous tissue should be taken into consideration for appropriate management (1)

A long segment of urethral stricture is the indication for surgical correction. Strictures longer than $2 \mathrm{~cm}$ that are not suitable for anastomotic repair therefore, require substitution urethroplasty, where a graft is used. Whilst substitution urethroplasty is an established and accepted treatment there is currently no clear consensus on the best graft material (2).

Pedicled and free grafts have been used including split and full-thickness skin grafts (genital and extra-genital), bladder mucosa, colonic mucosa, tunica vaginalis, tissue-engineered grafts, and intra-oral mucosa (buccal or lingual) $(3,4)$.

Long-term results of scrotal and extra-genital skin are disappointing as non-hirsute full-thickness skin grafts are associated with stricture recurrence (5). Among the mucosal grafts, the buccal mucosa has proved to be a versatile and successful urethral substitute. The use of buccal mucosa graft (BMG) for urethral reconstruction was first reported, in 1894 (6). It is relatively easy to obtain and manipulate, is a wet epithelium, and has a excellent immunity. It is less prone to stricture recurrence especially in the presence of lichen sclerosus. Today the buccal mucosa is the preferred donor site for urethral stricture repair (7). However, its harvesting may be associated with donor site morbidities, such as perioral numbness, difficulty in opening the mouth and less commonly, dry mouth, and long term complications such as scarring (8).

The thick buccal mucosa epithelium with dense submucosa and extensive capillary network assures rapid neovascularisation and early access of nutrients from the wound bed $(4,9,10)$.

Herein we report our experience with dorsal BMU for the primary repair of anterior urethral strictures.

\section{Materials AND Methods}

After ethics committee approval, we reviewed data of 24 patients with anterior urethral stricture undergoing buccal mucosal urethroplasty (BMU) between September 2010-September 2015. After excluding 5 patients, who had follow-up less than 6-months, and 3 patients lost to follow-up, 15 patients, were finally analyzed. Patients with short stricture $(<2.5 \mathrm{~cm})$, strictures with caliber $>6$ $\mathrm{mm}$, complex strictures (strictures associated with abscess, fistula), posterior urethral strictures, history of oral surgery, visible oral mucosal changes, restricted mouth opening, and previous failed urethroplasty were excluded from the study.

The retrospective data of patients undergoing BMU were collected. Patient characteristics and baseline data were recorded. All patients underwent uroflowmetry (UFM), urine culture/sensitivity, urethrography, and cystourethroscopy. The oral mucosal characteristics were assessed in all patients during the initial workup. Single stage dorsolateral onlay graft urethroplasty was applied in all patients. After intubation under general anesthesia, initially perineal dissection was done. Following midline perineal incision, bulbospongiosus muscle was dissect- 
ed. The urethra was mobilized from cavernosa only on one side beyond midline to preserve the vascular supply. The urethra was opened longitudinally on lateral side. The stricture length was measured. Graft was harvested $2 \mathrm{~cm}$ longer than the measured stricture length, as there is approximate $10 \%$ contraction over time, and width of $15-25 \mathrm{~mm}$ was taken to provide a lumen of at least $24 \mathrm{Fr}$ after tubularization.

For BMU, graft taking was started with the submucosal infiltration of xylocaine and adrenaline $(1: 100,000)$ under the marked buccal mucosal patch. Approximately, 0.5-1.0 cm mucosa from Stenson's duct were left to prevent duct injury. All defects were left open to prevent tension, pain, and distortion.

After graft harvest, fat removal was done till the graft appeared creamy white. Graft and urethral plate were stretched to avoid postoperative diverticula and postvoid dribbling; attached on cavernosal bodies and after that it was sutured to the urethral plate in dorsolateral onlay fashion.

Finally, the urethra was closed over 16 Fr silicone catheter with 4-0 vicryl. All patients were given intravenous antibiotics for 1 days, followed by oral for 5 days. The patient was allowed clear fluids or liquid diet on day 1 and then gradually soft and regular diet in the following days. In the postoperative period patients were asked to outpatient clinic for reporting the complications.

The patients were followed at 1, 3, 6 and 12 months after surgery. Voiding symptoms, questionnaires, and UFM were done in all as primary screening for stricture recurrence. Urethrography and cystourethroscopy were done as a secondary screening only if the patient developed obstructive symptoms or UFM showed $\mathrm{Q}_{\max }<15 \mathrm{ml}$ after ruling out lower urinary tract infection.
The success of urethroplasty was considered as the primary outcome of the study. We defined success as the absence of any obstructive symptoms and no need of subsequent procedures, such as dilatation, cystourethroscopy, and internal urethrotomy.

\section{Statistical evaluation}

Data were entered in the MS Excel and analyzed in SPSS version 20 software (IBM Corp. IBM SPSS Statistics for Windows, Version 16.0). Continuous variables were presented as means \pm standard deviation. Proportions (percentages) were calculated for discrete variables.

\section{RESULTS}

Characteristics of patients and in follow up periods are depicted in Table 1. Mean age was $53.7 \pm 13.6$ The stricture length ranged from 3 to $6 \mathrm{~cm}$ (mean $4.4 \pm 0.8$ The success rate for BMG was $67.7 \%$ at $12^{\text {th }}$ month. Three patients presented with voiding difficulty in the $3^{\text {rd }}$ month, one in the next 12 months, had urethral restenosis. One patient had fistula formation at $6^{\text {th }}$ month postoperatively.

One patient was reoperated with internal urethrotomy and subsequent internal urethrotomy with urethroplasty, one with urethroplasty and subsequent urethral dilation, one with internal urethrotomy and subsequent urethral dilation, one with fistula closure. Early and immediate graft donor site complications were seen in all patients.

Pain, difficulty in chewing and numbness of donor site was the most common early complication, but these were mild and transient in all patients. Salivary flow changes were not seen in any patient.

\section{Table 1.}

Characteristics of patients undergoing buccal mucosal urethroplasty.

\begin{tabular}{|c|c|c|c|c|c|c|c|c|}
\hline Age & Etiology of stricture & Stricture length $\mathrm{cm}$ & Comorbidity & $3^{\text {rd }}$ month & $6^{\text {th }}$ month & $12^{\text {th }}$ month & Reoperation & Dilation \\
\hline 73 & Infection (Fournier) & 6.0 & $\mathrm{DM}+\mathrm{HT}$ & stricture & normal & normal & & + \\
\hline 50 & Hypospadias repair & 4.0 & none & stricture & normal & stricture & Urethroplasty & - \\
\hline 47 & Trauma & 4.0 & none & normal & normal & normal & & - \\
\hline$\overline{44}$ & Trauma & 5.0 & none & normal & normal & stricture & Urethroplasty & - \\
\hline 39 & Trauma & 4.0 & none & normal & normal & normal & - & - \\
\hline 64 & Instrumentation (TUR-P) & 4.0 & HT & normal & normal & stricture & Internal urethrotomy & + \\
\hline 34 & Trauma & 4.0 & none & normal & normal & normal & & - \\
\hline 68 & Infection & 5.0 & none & normal & normal & normal & & - \\
\hline 38 & Hipospadias repair & 5.0 & HT & normal & fistula & fistula & Fistula closure & - \\
\hline 63 & Infection (urethritis) & 5.0 & $\mathrm{DM}+\mathrm{HT}$ & normal & normal & normal & - & - \\
\hline 56 & $\begin{array}{c}\text { Instrumentation } \\
\text { (urinary catheter insertion) }\end{array}$ & 3.0 & $\mathrm{DM}+\mathrm{HT}+\mathrm{CAD}$ & normal & stricture & stricture & - & + \\
\hline 75 & Lichen sclerosis & 4.0 & HT & normal & normal & normal & & - \\
\hline 62 & Instrumentation TURP & 5.0 & $\mathrm{DM}+\mathrm{HT}$ & normal & normal & normal & - & - \\
\hline 37 & Hypospadias repair & 3.0 & none & normal & normal & normal & . & - \\
\hline 55 & Trauma & 5.0 & DM & stricture & stricture & stricture & Urethroplasty & + \\
\hline
\end{tabular}

DM: Diabetes Mellitus; HT: Hypertension; CAD: Coronary artery disease. 


\section{Discussion}

Severe and longer urethral strictures require substitution urethroplasty. Miscellaneous tissues have been used in the past however, in the last decade, buccal mucosa gained popularity as the best substitute material for urethral reconstruction (11).

Buccal mucosa is a convenient donor site for augmentation urethroplasty because of its thick epithelium, high content of elastic fibers and rich vascularity due to pan laminar plexus, and good graft uptake (12). It is easy to obtain, readily available, compatible with wet environment, and butress the local immune status with its increased amount of IgA, resistant to infection and has better healing features as demonstrated by rapid healing of aphthous ulcers. A systematic review and meta-analysis of urethral reconstruction with buccal mucosa or penile skin graft (PSG) revealed a success rate of $85.9 \%$ with buccal mucosa and $81.8 \%$ with PSG (13).

A $90 \%$ success rate has been reported when using buccal mucosa dorsal onlay free grafts for the management of bulbar urethral strictures. Whereas a $87 \%$ success rate when using buccal mucosa urethroplasty to treat 24 pendulous strictures. Our series is a 5-year retrospective review, of 24 consecutive patients who underwent buccal mucosa urethroplasty. It is not within the scope of this paper to discuss, in detail, the surgery involved as it is well described in previous studies, but rather to report the outcome following its use.

In addition, the nuances such as dorsal versus ventral onlay, one versus two-stage techniques, and the choice of surgery/graft depending on whether the stricture is bulbar pendulous or meatal, are not mentioned in this paper. The overall medium to long-term success rate in our small series is $67.7 \%$ at $12^{\text {th }}$ month (when stricture recurrence after stage 1 is considered failure).

This lower success rate may be explained with high number of strictures due to trauma and previous hipospadias repair. In the present series, pain, difficulty in chewing and numbness of donor site were the most common early complication. No long-term complications, such as sensory nerve deficit, or damage to Stenson's duct occurred. In paralel to this observation, several authors have reported no important oral complications in their respective studies (14-17). However, in a retrospective review of 49 male patients it was found that $15(26 \%)$ had residual perioral numbness after 6 months, with 5 (9\%) having persistent restriction in mouth opening.

Considering the serious complications, mouth tightness due to oral scar development rates ranged from 9\% to $32 \%$ in some series with a single serious hematoma case on the graft removal site in the buccal mucosa (18-20). In association with follow-up duration, it is known that all urethral grafts tend to shrink over time. One can claim that, a longer follow-up period is likely to produce poorer results. In this present study the mean follow-up period of 12 months may be the limitation of the study.

The other limitation of the study is its retrospective nature. Neverthless, in the presence of different stricture etiologies and various parameters such as location, length and surgical techniques, a large prospective ran- domised trial comparing graft materials and/or techniques would be extremely difficult to design. Therefore, despite the relatively small number of patients of our study, the present results seem to contribute modestly to the fact that BMU is a suitable method in substitution urethroplasty.

\section{Conclusions}

Reconstruction of a urethral stricture, not treatable with end-to-end anastomosis, impose a difficult surgical problem. Although the sample size is small, our study suggest that anterior urethral strictures up to $6 \mathrm{~cm}$ in length may be effectively managed with BMU.

The buccal mucosa is easy to obtain and handle, therefore BMU can be safely and effectively managed outside high volume institutions. Furthermore, the rate of complications, from both a urological and oropharyngeal perspective is low.

\section{References}

1. Jordan GH, McCammon KA. Surgery of the penis and urethra. Campbell-Walsh urology. 10th ed. Philadelphia: Elsevier Saunders. 2012; p. 956-1000

2. Andrich DE, Mundy AR. What is the best technique for urethroplasty? Eur Urol. 2008; 54:1031-1041

3. Lumen N, Oosterlinck W, Hoebeke P. Urethral reconstruction using buccal mucosa or penile skin grafts: systematic review and meta-analysis. Urol Int. 2012; 89:387-394.

4. Mangera A, Chapple C. Management of anterior urethral stricture: an evidence-based approach. Curr Opin Urol. 2010; 20:453458.

5. Rogers HS, McNicholas TA, Blandy JP. Long-term results of onestage scrotal patch urethroplasty. Br J Urol. 1992; 69:621-628.

6. Sievert KD, Seibold J, Schultheiss D, et al. Reconstructive urology in the change, from its beginning to the close future. Urologe A. 2006; 4:52-8.

$7 l$ Bhargava S, Chapple CR. Buccal mucosal urethroplasty: is it the new gold standard? BJU Int. 2004; 93:1191-1193

8. Wood DN, Allen SE, Andrich DE, et al. The morbidity of buccal mucosal graft harvest for urethroplasty and the effect of nonclosure of the graft harvest site on postoperative pain. J Urol. 2004; 172:580-3.

9. Bhargava S, Chapple CR. Buccal mucosal urethroplasty: is it the new gold standard? BJU Int. 2004; 93:1191-1193.

10. Dubey D, Vijjan V, Kapoor R, et al. Dorsal onlay buccal mucosa versus penile skin flap urethroplasty for anterior urethral strictures: results from a randomized prospective trial. J Urol. 2007; 178:2466-2469

11. Djordjevic ML. Graft surgery in extensive urethral stricture disease. Curr Urol Rep. 2014; 15:424.

12. Pansadoro V, Emiliozzi P, Gaffi M, et al. BMU in the treatment of bulbar urethral strictures. Urology. 2003; 61:1008-1010.

13. Lumen N, Oosterlinck W, Hoebeke P. Urethral reconstruction using buccal mucosa or penile skin grafts: systematic review and meta-analysis. Urol Int. 2012; 89:387-394.

14. Dubey D, Kumar A, Mandhani A, et al. Buccal mucosal ure- 
throplasty: a versatile technique for all urethral segments. BJU Int. 2005; 95:625-629.

15. Grady JD, McCammon K, Schlossberg SM, et al. Buccal mucosal graft for penile urethral strictures. J Urol. 1999; 161:375.

16. Morey AF, McAninch JW. Technique of harvesting buccal mucosa for urethral reconstruction. J Urol. 1996; 155:1696-1697.

17. Eppley BL, Keating M, Rink R. A buccal mucosal harvesting technique for urethral reconstruction. J Urol. 1997; 157:1268-1270.
18. Dublin N, Stewart LH. Oral complications after buccal mucosal graft harvest for urethroplasty. BJU Int. 2004; 94:867-869.

19. Caldamone AA, Edstrom LE, Koyle MA, et al. Buccal mucosal grafts for urethral reconstruction. Urology. 1998; 51(5A Suppl):15-19.

20. Kane CJ, Tarman GJ, Summerton DJ, et al. Multi-institutional experience with buccal mucosa onlay urethroplasty for bulbar urethral reconstruction. J Urol. 2002; 167:1314-1317.

\section{Correspondence}

Basri Cakiroglu, MD (Corresponding Author)

drbasri@gmail.com

Ersan Arda, MD

Hisar Intercontinental Hospital, Department of Urology,

Saray Mh.Siteyolu Cad. No.7 34768 Umraniye, Istanbul, Turkey

Orhun Sinanoglu, MD

Maltepe University, Medical School Department of Urology, Istanbul, Turkey 